\title{
Making It Real: From Telling to Showing, Sharing, and Doing in Psychiatric Education
}

\author{
Andrés Martin (iD ${ }^{1-3}$ \\ Marco A de Carvalho Filho (D) 3 ,4 \\ Debbie Jaarsma ${ }^{3,5}$ \\ Robbert Duvivier ${ }^{3,6}$ \\ 'Child Study Center, Yale School of \\ Medicine, New Haven, CT, USA; \\ ${ }^{2}$ Simulated Participant Program, Teaching \\ and Learning Center, Yale School of \\ Medicine, New Haven, CT, USA; ${ }^{3}$ Center \\ for Educational Development and \\ Research in Health Sciences (CEDAR), \\ Lifelong Learning, Education and \\ Assessment Research Network \\ (LEARN), University Medical Center \\ Groningen, Groningen, the Netherlands; \\ ${ }^{4}$ School of Medical Sciences, University of \\ Minho, Braga, Portugal; ${ }^{5}$ Faculty \\ of Veterinary Medicine, University of \\ Utrecht, Utrecht, the Netherlands; \\ ${ }^{6}$ Parnassia Psychiatric Institute, The \\ Hague, the Netherlands
}

Objective: Innovations in contemporary medical education could inform remedies to address enduring challenges such as the marginalization and stigmatization of psychiatry, of mental illnesses, and of those affected by them.

Methods: In blending the works of Bleakley, Bligh, and Brown (2011) and of Kumagai and Naidu (2015), we developed an overarching heuristic with practical relevance and concrete applications to psychiatric education.

Results: We identify three areas to enhance psychiatric education embedded into this blended framework: 1) Showing, or the more accurate depiction or imaging of mental illnesses and of psychiatric practice, as exemplified by the incorporation into didactic content of asynchronous video-based clinical materials produced with specific educational objectives in mind; 2) Sharing, or addressing the image problem of mental illnesses, of those living with or affected by them, and of psychiatry as a profession, as exemplified by psychiatrists embracing their role as experts by professional and personal experience when sharing their own journeys with mental illness, treatment, and recovery; and 3) Doing, or reimagining reflective psychiatric practice, as exemplified by the novel methodology of co-constructive patient simulation (CCPS), through which learners can engage in reflective practice and supervision in a participatory and democratic setting that does not privilege participants' hierarchical standing.

Conclusion: The blended model and the sample applications we describe offer a range of teaching, learning, and professional development opportunities, should psychiatric educators choose to pursue them and reap their promise.

Keywords: medical education, psychiatry, reflective practice, simulated patients, stigma, video-enhanced didactic

\section{Introduction}

Do not tell me the moon is shining; show me the glint of light on broken glass.

- Anton Chekhov: Letters (1899)

Psychiatry as a medical discipline continues to be poorly understood, maligned, or insufficiently incorporated into the broader house of medicine. ${ }^{1}$ Mental illnesses and those living with or affected by them are disproportionately stigmatized and disenfranchised from their communities - including from the medical community charged with their care, as reflected by excess mortality among psychiatric patients. ${ }^{2}$ Even as psychiatry has made extraordinary strides in the understanding, prevention, treatment, and rehabilitation of mental illnesses, the field as a whole continues to have what may be construed as an "optics" problem. ${ }^{3}$

When it comes to the depiction of what psychiatrists do, the field may have fallen short. ${ }^{4}$ The field may be hampered by difficulties inherent to "opening the
Correspondence: Andrés Martin

Yale Child Study Center, 230 South Frontage

Road, New Haven, CT, 06520-7900, USA

Tel + I 203-494-2355

$\mathrm{Fax}+\mathrm{I} 203-785-7400$

Email andres.martin@yale.edu 
black box" of the consultation or supervisory "rooms where it happens". This has contributed to a prevailing perception of psychiatry as an inscrutable profession. The ways in which psychiatrists are trained, particularly in the domains of psychotherapy and interpersonal communication, are likewise opaque and have not fundamentally changed in their format for decades. Psychotherapy has certainly evolved in its approaches, content, and efficacy, but the overall approach to supervision toward its application has not kept pace in its incorporation of novel pedagogies. ${ }^{5}$ Specifically, the model of bringing clinical material to supervision only after seeing patients has forestalled the ability for trainees and practicing psychiatrists to optimize their skills before applying them to patients, including when honing skills or introducing new approaches.

The portrayal of what people with mental illnesses actually look like is similarly handicapped. The broader public often learns about mental illnesses from movies, television, and Internet depictions that are often incorrect, exaggerated, ${ }^{6}$ or that disproportionately link mental illness to aggression, violence, homelessness, grim treatment settings, or guarded prospects for recovery or inclusion. ${ }^{7}$ In its effort to depict psychopathology, the field is at a disadvantage when compared to other medical disciplines by the limited number of images through which to exemplify its paradigmatic conditions. Most medical specialties have a rich array of objective findings and visual means through which to support education. In addition to outwardly visible and objective signs, other specialties can rely on diagnostic imaging, even on images of tangible biological tissue, that elusive component so far removed from psychiatry's grasp. These limitations in portraying mental illnesses are further compounded by matters of privacy, anonymity, and the competence to provide informed consent, which can be directly compromised by the illness itself.

We posit that the combination of these shortcomings and inherent limitations has contributed to the misunderstanding, stigma, and devalued perception commonly assigned to psychiatry within the broader house of medicine and society at large. ${ }^{4}$ In this article, we explore two theoretical frameworks that when combined can inform remedies to address these enduring problems. We next describe three major areas ripe for improvement, providing relevant examples for each, including from our own research. We conclude by proposing future directions and offering an entreaty to join us in these efforts.

\section{Two Theoretical Frameworks}

\section{Identity, Power, and Location}

Alan Bleakley, John Bligh, and Julie Brown (hereafter $\mathrm{BB} \& \mathrm{~B})^{8}$ articulated in 2012 a new framework for medical education centered on the three core elements of identity, power, and location. When combined, these elements yield their summary definition of medical education as the multiplicative interaction of "identity $\times$ location $\times$ power"that is, as more than the mere sum of its constituent parts.

In the context of medical education's charge to "produce" physicians and other healthcare providers (such as psychiatrists), BB\&B conceptualized identity as the stepwise progression from "being" to "becoming", an iterative process of "invention rather than discovery", of lifelong "construction and reconstruction". Such developmental growth is in turn undergirded by three learning theories, each emphasizing in different ways how medical education should optimally take place in a context that is patientcentered, socially connected, and grounded "in the heat of practice ... at the coalface of activity and often in the heat of others' conflict". Cultural-Historical Activity Theory $(\mathrm{CHAT})^{9}$ rubs against competitive and goal-directed individual learning, highlighting instead the role of education in socially connected and collaborative networks. In Actor-Network Theory (ANT), ${ }^{10}$ "identity" is dissolved in favor of "actor-networking", where "actors" include not only patients and colleagues-humans-but also the artifacts of daily practice such as computers, electronic health records, instruments, books, and journal articles. Finally, Communities of Practice ${ }^{11,12}$ centers on gaining experience, knowledge, and problem-solving skills as part of a group of like-minded peers committed to a shared goal, such as the creation of cohesion and specific expertise as increasingly subspecialized professionals. As one concrete example, ${ }^{13}$ clinician-educators focused on child psychiatric disorders (identity) may apply state-of-the-art skills in clinical practice and medical education (collaboration) by using simulated patients and distant learning tools (artifacts) to address their very specific collective needs (community).

A second component for the progressive medical education envisioned by $\mathrm{BB} \& \mathrm{~B}$ was a long overdue realignment in the ossified power structures within medicine. Such correction had become necessary in response to entrenched practices that were overly paternalistic, hierarchical, and top-down in their approach — ones in which "doctor (invariably) knew best". This kind of medicine 
was partly fraught by military-based early attempts to standardize healthcare education, including in the birth of modern medicine and nursing. The functionality of early and highly structured healthcare environments relied on rigid structures based on sovereign power, in which the sovereign asserts himself over others (the masculine descriptor being all too historically accurate in medicine). Sovereign power is "reproductive of conventional, vertical authority structures", stifling innovation and growth along the way. By contrast, capillary power is horizontally aligned through networks that are productive, transformative, and nurturing. The nurturing quality can be understood through an analogy "not modeled on trees (ever more precarious in their vertical growth) but on rhizomes and fungal mycorrhizae, the tangled horizontal growth networks" ${ }^{\prime \prime}$ through which tree roots feed, communicate, and grow with each other with little fanfare. In brief, medical education that builds among learners in a horizontal (capillary) fashion yields stronger growth than what can ensue from a top-down (sovereign) model in which instructor leads and learners follow.

The third and final part of BB\&B's model pertains to location, both physical and conceptual. On the physical side, large teaching hospitals continue to provide the (brick and mortar) bedrock in which medical education is grounded. Commonly vertical, edifices can echo power structures; in their classic form, they can contribute to isolation and siloing rather than social engagement. Modern architectural approaches have been thoughtful in taking into consideration patient-centered needs (eg, private and family-friendly rooms, soft lighting, noise-muffling materials) and workflows that enhance collaboration between and across providers (eg, centrally placed nursing stations, cross-disciplinary break rooms). Along those lines, a hegemony of place can give way to a reimagining of space - ranging from the bedside and the consulting room to the new affordances of virtual communication, mobile devices, and off-site care as in telepsychiatry. On a conceptual level, and cognizant that anyone can be "dulled by the location in which they work", 8 medical practice can benefit from "deterritorialization", through which clinicians are not inevitably tethered to their desks or offices, but can rather return to the bedside ("patientside" may be more accurate for psychiatry) and indeed "follow the actors" to their own locations, be they homes, distant communities, or sites of devastation, as in the case of disaster psychiatry.

\section{Reflection, Dialogue and the Possibilities of Space}

In The Reflective Practitioner, one of medical education's foundational texts, Donald Schön created a framework through which to engage in clinical work while being fully present in the patient encounter. ${ }^{14}$ His model can be simplified into a tripartite approach to reflection that is organized temporally: in practice ("while doing"); on practice ("having done"); and for practice ("toward doing"). Building on that seminal scaffold, Arno Kumagai and Thirusha Naidu ${ }^{15}$ encouraged a deepening of reflective practice that through the triad of safety, intentionality, and liminality allows for encounters in which the patient is "no longer reified as an object to be worked on but an active subject to be worked with". ${ }^{16}$

Safety encompasses confidentiality, supportive presence, and non-judgmental active listening, preconditions for the next two components. Intentionality begins with cordoning time off, away from the daily demands on clinicians' attention and energy. When effectively combined, safety and intentionality can pave the way for moving from discussions to dialogues, exchanges that fundamentally differ in their emphasis (objectivity vs subjectivity and intersubjectivity) and goals (solutions or answers vs new questions or possibilities). Liminality refers not only to the transient and ephemeral quality of each clinical encounter but also to an awareness regarding "the transitional nature of critically important periods of professional identity development." The works of these pioneers in reflective practice are a reminder of how "at its core, medicine is a type of applied humanism, that is, the application of science in recognition of human values and in the service of human needs". ${ }^{16}$

\section{Frameworks Combined}

These two theoretical approaches can be fruitfully combined into an overarching heuristic with practical relevance and concrete applications to medicine in generaland to psychiatry in particular. When distilled to their essence, the work of $B B \& B$ can be conceptualized as pertaining to the practitioner's outfacing interactions: helping the growth and development of others (identity), rebalancing hierarchical relationships (power), and disrupting the places in which, and the means through which to learn (location). By contrast, the work of Kumagai and Naidu is largely directed inward, providing a rubric through which to reconcile and make sense of the practitioner's inner 


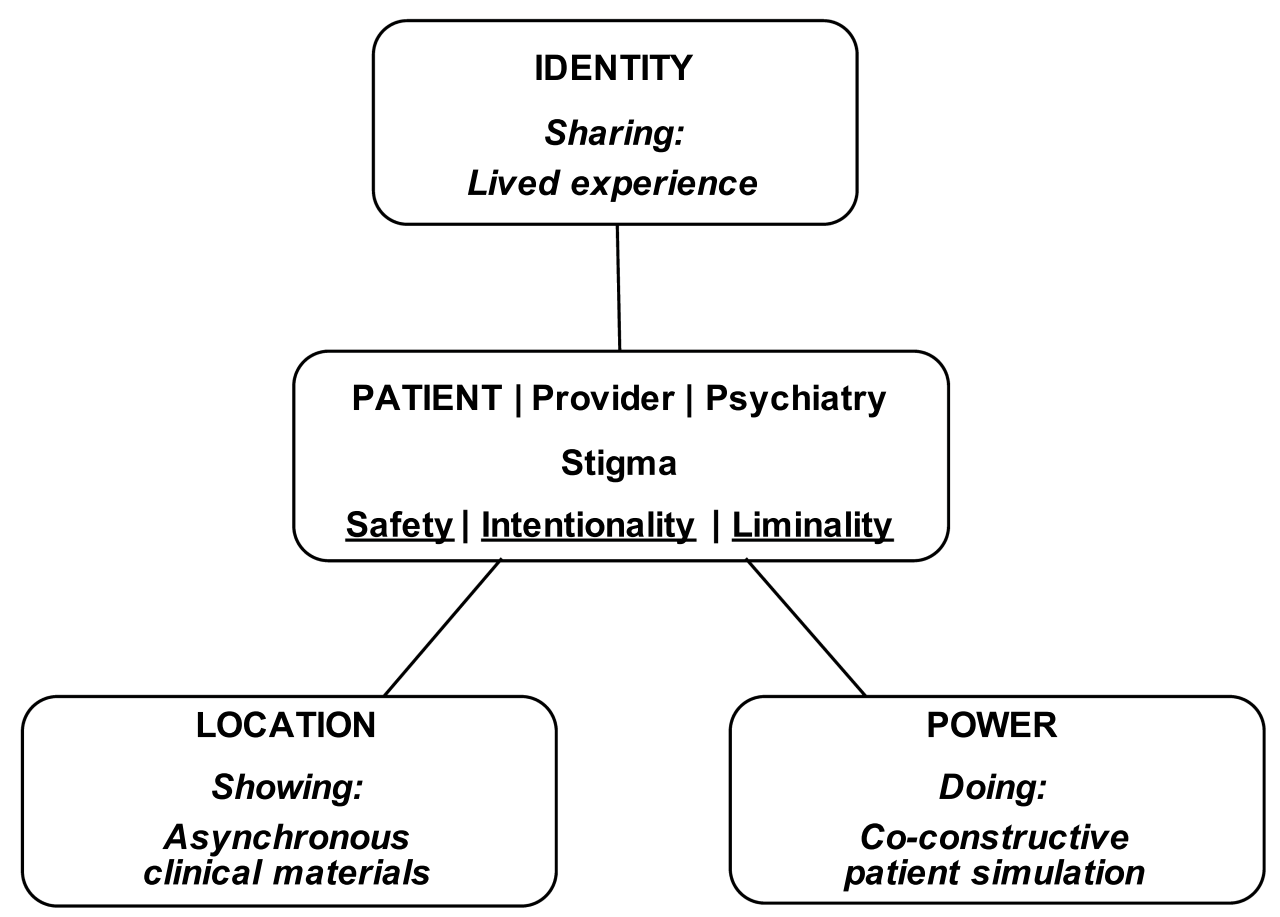

Figure I Two combined frameworks applied to psychiatric education.

Notes: All capitals: constructs derived from reference ${ }^{8}$; underline: constructs derived from reference ${ }^{15}$; Italics: three applied examples.

world - a means through which to overcome defaulting to a reactive or reflexive stance, and rather engage in a truly reflective practice. ${ }^{14}$

Figure 1 blends the two frameworks, centered around an alliterative core of patient, provider, and psychiatry. In proximity, and relevant to each of the three, is stigma, "defined as the shame and degradation meted out to members of social groups believed to be unworthy, dirty, or untouchable". ${ }^{17}$ Each of the three spokes radiating from the core includes applied examples organized along the constructs of showing, sharing, and doing. In the next section, and as summarized in the Table 1 matrix, we go on to elaborate each of these interacting elements, incorporating examples, applications, and potential remedies specifically relevant to patient- and learner-centered psychiatric education.

\section{Theory Applied: Enhancing Psychiatric Education Showing: Imaging Mental Illnesses and Psychiatric Practice}

As a medical discipline, psychiatry has struggled with an imaging challenge to provide accurate and realistic portrayals of its activities and the mental illnesses under its purview. The main source for the lay public to gain a foothold into the otherwise hazy world of mental illness may be disorienting experiences with psychopathology, whether personal or among loved ones, or through sensationalist representations in the media. Trainees at all levels of the healthcare professions are generally exposed, when exposed at all, to chronically ill hospitalized patients that represent but the tip of a severity iceberg. Psychiatric patients sharing their living experience openly is the most fruitful and ultimately realistic depiction of mental illness, but one that can be logistically complicated, burdensome (especially for what may come to feel as "repeat performances") and that can become subtly coercive. Curated movie or popular media selections may fall flat or be overly dramatic, and written vignettes may be dry or unrealistic.

An alternative approach is the incorporation of videobased materials produced with specific educational objectives in mind. Such materials, designed to be archival and enduring, offer several logistic and educational advantages: they can be tailored as "bespoke" items, including through design to the specificities of international, regional, or local realities; they provide standardized portrayals; they can be shared broadly via open-access websites such as YouTube or Figshare (figshare.com); and they do not overburden patients generous enough to share their 
Table I Matrix of Two Theoretical Frameworks Applied to Psychiatric Education

\begin{tabular}{|c|c|c|c|}
\hline & $\begin{array}{c}\text { Location } \\
\text { Showing: } \\
\text { Asynchronous Clinical } \\
\text { Materials }\end{array}$ & $\begin{array}{l}\text { Identity } \\
\text { Sharing: } \\
\text { Lived Experience }\end{array}$ & $\begin{array}{c}\text { Power } \\
\text { Doing: } \\
\text { Co-Constructive Patient Simulation }\end{array}$ \\
\hline Safety & $\begin{array}{l}\text { - Abiding by best practices for } \\
\text { simulated patients } \\
\text { - Paying special attention to the } \\
\text { hiring of underage actors } \\
\text { - Respecting patients' decision to } \\
\text { participate or decline } \\
\text { - Paying attention to dual agency } \\
\text { by separating clinical from } \\
\text { educational agendas } \\
\text { - Ensuring ability to provide } \\
\text { informed consent }\end{array}$ & $\begin{array}{l}\text { - Social contact between individuals with } \\
\text { and without mental illnesses is the most } \\
\text { effective destigmatizing intervention in } \\
\text { psychiatry } \\
\text { - Providing non-judgmental listening and } \\
\text { unconditional support to those sharing } \\
\text { generously } \\
\text { - Ensuring the confidentiality of all } \\
\text { participants }\end{array}$ & $\begin{array}{l}\text { - CCPS is a novel medical education } \\
\text { approach that provides a participatory } \\
\text { alternative to traditional supervision and } \\
\text { training } \\
\text { - Learning objectives are set by learners, } \\
\text { informed by topics difficult to openly talk } \\
\text { about } \\
\text { - Experiencing the clinical struggles and } \\
\text { challenges of peers-and one's own-in an } \\
\text { open and emotionally secure space }\end{array}$ \\
\hline Intentionality & $\begin{array}{l}\text { - Embedding materials that } \\
\text { showcase clinical realities requires } \\
\text { buy-in from instructors and } \\
\text { curriculum developers } \\
\text { - Destigmatizing patients by } \\
\text { humanizing the "face" of mental } \\
\text { illnesses }\end{array}$ & $\begin{array}{l}\text { - Deciding to acknowledge vulnerabilities } \\
\text { requires a deliberate act of bravery } \\
\text { - Destigmatizing providers by addressing } \\
\text { maladaptive perfectionism through } \\
\text { a showcasing of the mental health challenges } \\
\text { and human fallibility of clinicians } \\
\text { - Addressing self-stigma } \\
\text { - Modeling self-compassion }\end{array}$ & $\begin{array}{l}\text { - "Making" time where it is impossible to } \\
\text { "find" it demands programmatic and } \\
\text { personal commitment } \\
\text { - Destigmatizing psychiatry by exporting } \\
\text { the field's expertise to other specialties } \\
\text { and healthcare disciplines }\end{array}$ \\
\hline Liminality & $\begin{array}{l}\text { - Simulated patients are } \\
\text { professional actors who inhabit } \\
\text { scripts to embody the lives of real } \\
\text { patients } \\
\text { - Committing to authentic } \\
\text { representation } \\
\text { - Opening the "black box" of the } \\
\text { "room where it happens" }\end{array}$ & $\begin{array}{l}\text { - In offering their whole selves, providers } \\
\text { leave the comfort of their outwardly curated } \\
\text { professional personas } \\
\text { - In publicly owning their experience as } \\
\text { patients, providers blur the boundaries } \\
\text { between their two "roles" }\end{array}$ & $\begin{array}{l}\text { - Participants are at critical transition } \\
\text { points in their professional development } \\
\text { - Videoconferencing and other web-based } \\
\text { means offer hitherto unimaginable } \\
\text { experiences that permit interactivity in } \\
\text { real time across sites, distances, and time } \\
\text { zones }\end{array}$ \\
\hline
\end{tabular}

personal stories, who by virtue of being able to attend a lecture during working hours, tend to favor the participation of more privileged individuals.

Simulated patients (SPs), alternatively called simulated participants ${ }^{18}$ and first introduced to medical education in 1963, have taken on an important role in the education of healthcare professionals. ${ }^{19}$ The use of SPs in psychiatric education has been criticized as limited in its application and "most problematic for teaching psychotherapy and assessing complex interpersonal skills, such as empathic responsiveness". ${ }^{20}$ However, a growing literature, as recently reviewed, ${ }^{21}$ reveals that SP use can in fact be fruitfully applied as one potential remedy for the discipline's imaging woes. The unique strengths of SPs in psychiatry may in fact reside in the opportunity they provide to delve deeply into interpersonal complexity.
Examples from our own work include portrayals of psychiatric: 1) illnesses, as through an archive of mental status exam representations ${ }^{22}$ and a related exercise tool for learners to apply their knowledge; ${ }^{23}$ and of adolescent depression, ${ }^{24}$ with variations underway that incorporate the specific realities of Black and transgender youth, including racism and transphobia, respectively; and 2) interventions, such as electroconvulsive therapy; ${ }^{25}$ addressing psychosexual health among adolescents; ${ }^{13}$ and on how to optimally "prescribe" AA/NA in the care of patients with substance use disorders. ${ }^{43}$

Videotaped materials are inherently applied in an asynchronous way that takes the patient to the learner, an educational disruption of location that complements patient-centered learning. Even as the reverse arrangement is the ultimate patient-centered goal, taking the learner to 
the patient is not always practical or even feasible, particularly to outpatient and community-based settings in which the majority of psychiatric care takes place, or into individual psychotherapy settings that are cordoned as off-limit "black box" spaces.

To ensure the safety of asynchronous encounters with SPs, educators need to adhere to best practices ${ }^{26}$ and pay particular attention to ethical and legal considerations pertaining to the use of underage actors, not to mention the emotional burden they may be asked to take on. ${ }^{27}$ To be intentional in the use of enduring materials, instructors and curriculum developers need to buy into the enterprise, starting with exposure to, and familiarity with the opportunities of the asynchronous video format, as of the technical requirements necessary to embed clips seamlessly into didactic activities. A side benefit to using SP-based materials - one intentionally designed — is to help address stigma through portrayals that are humane, accurate, and realistic in their therapeutic, reintegrative, or rehabilitative promise. Educators should, whenever possible, commit to authentic representation in their use of SPs, as in the hiring of individuals with physical or developmental disabilities when exemplifying those conditions. ${ }^{28}$ Finally, by adhering to scripts through which to embody individuals with psychopathology, SPs intrinsically personify liminality through their trade, as does the opening of otherwise inaccessible locations, such as psychotherapeutic spaces.

Actual patients, rather than simulated, can also be incorporated into, and indeed involved in the creation of enduring materials designed for either clinical or research purposes. For example, Amsalem et al have used short videos (under 2 minutes) of patients with schizophrenia in order to destigmatize the condition and increase treatment-seeking among those affected. $^{29,44}$ Their interventions, proven effective in randomized controlled trials with over 1000 participants, hold promise for messaging on a large scale through a format that is attuned to the ubiquity of handheld devices and to increasingly short attention spans. In order to recruit patients, educators must respect their desire for privacy and their willingness (or reluctance) to participate. Clinicians need to be attentive to dual agency and the potential for furtive coercion in approaching their own patients, particularly those with cognitive decline or a thought disorder that may render them unable to provide truly informed consent to make their likeness available for broad distribution.

\section{Sharing: Addressing the Image Problem of Mental IIIness and Psychiatry}

Patients with mental illnesses willing to share their lived experiences candidly are an invaluable educational resource. Perhaps unsurprisingly, the most effective destigmatizing intervention in psychiatry is social contact between individuals with and without mental illnesses. ${ }^{30}$ Addressing the stigma of mental illness has additional urgency for healthcare professions in general, and for physicians in particular. Internalized stigma (or selfstigma) is the most pervasive obstacle to efforts designed to increase and support treatment-seeking among providers, ${ }^{31}$ and to ultimately save lives lost to suicide. In keeping with social contact-based approaches to a population with heightened vulnerability, an innovative approach with undergraduate nursing students in Australia harnesses exposure to "consumer academics", individuals employed in university academic roles who teach students based on personal lived experiences with mental illness and mental health service usage. ${ }^{32}$

Closer to the direct experiences of care providers, physicians and other healthcare professionals generous enough to share their own trajectories with mental illness can have a profound impact on their peers. With specific content knowledge and clinical expertise, affected psychiatrists can be optimally fit to the task as dual experts. Sharing experiences living with mental illness is not a unique charge to psychiatry and stands to benefit all branches and stages of medical education. However, psychiatrists have the optimal training, and perhaps the moral obligation, to further engage in, and develop this practice and relevant scholarship. The sharing of experience living with mental illness can provide a "concreteness" to exemplify subjective experiences at the core of what may be otherwise elusive conditions. Personal testimonies that highlight recovery and reintegration are potent antistigma interventions $^{33}$ that can lead to improvements in wellness, self-care, treatment-seeking and adherence, and perhaps ultimately suicide prevention. Psychiatrists who have successfully navigated mental illness may be considered experts by professional and personal experience and be especially well suited to the task. ${ }^{34}$

Our group has empirically tested the efficacy of such exposures. Working with second-year medical students, 
we demonstrated reductions in depression-related stigma after exposure to two psychiatrists (one senior, one midcareer) sharing openly their symptoms, treatment, recovery, and ongoing adjustment to their living (rather than lived) experiences. ${ }^{35}$ We replicated this finding twice: one in a second cohort of medical students in the same school, ${ }^{36}$ and another in a multisite cohort of physician assistants, ${ }^{37}$ in which the sharing, critically, was undertaken by senior physician assistants, ie, members of the same profession.

Guild membership, or the socialization into a community of practice, is central to identity formation as professionals, and sharing with fellow confrères the experience of living with mental illness a way for psychiatrists to engage with their whole selves - not their curated and edited outward personas - into training their next generation. But the charge for psychiatrists should by no means be limited to their fellow guild members: by intentionally shedding light on the risks of maladaptive perfectionism, modeling self-compassion, and showcasing how mental health challenges are common, fallibility normative, and seeking and engaging in treatment can be life- and careersaving, psychiatrists have much to offer a house of medicine that is hurting. In putting to practice the dictum for healers to heal themselves, psychiatrists can help destigmatize not just mental illness within the ranks of medicine, but psychiatry and psychiatrists along the way. In sharing their own experience as patients, psychiatrists enter a liminal space in which the boundaries of their personal and professional selves blend. Acknowledging personal shortcomings and vulnerabilities is an act of bravery that should only take place in the safety of confidential spaces suffused with the unconditional support and non-judgmental listening of peers and oft-undisclosed fellow sufferers.

\section{Doing: Reimagining Reflective Psychiatric Practice}

Learning the "ropes" of psychotherapy has followed the tired trope of classic supervision: one in which the trainee shares experiences that happened with their patient (past tense deliberate). In the back-and-forth that ensues, the trainee acquires new skills and insights that stand to benefit the patient in question, as hopefully many others. Alternative takes on supervision such as review of tapes or transcripts, observation through a one-way mirror, or directives offered through "bugs-in-the-ear" provide a closer approximation to a trainee's encounter. But still missing from the general supervisory equation are opportunities for experiencing and learning in real time, and for supervisor and trainee to grow alongside one another in a horizontal, rhizomic, and capillary fashion that upends the traditional, sovereign power structure and that contributes to building their shared community of practice. ${ }^{11,12}$ Co-constructive patient simulation (CCPS) is a novel methodology developed by our medical education research team through which learners can engage in the practice of psychiatry in a participatory and democratic way that does not privilege participants' hierarchical standing. ${ }^{38}$ CCPS holds promise as a new way of conceptualizing trainingand for moving it from a limited agenda of learning psychiatry to a creative one of becoming psychiatrists. ${ }^{39}$

The objectives and goals in CCPS are not supervisorcentered but rather set by trainees, based on difficulties they have encountered in their daily work. Trainees develop a script based on their experience, often a pastiche of several clinical challenges. The trainee, together with a supervisor familiar with the model, then work with a professional actor in making the script's patient come alive as an "avatar". To ensure the clinical accuracy of the actor's representation and the emotional legitimacy of the subsequent interaction, the trainee rehearses with the actor-in-role. In a separate session that follows, other peers or supervisors, blind to the specifics of the case, take turns in interviewing the trainee's "patient". As a silent witness to the interaction, the case-writing learner can see how their colleagues, including their supervisors, experience the selfsame challenge they had encountered before. The concluding debriefing component allows all participants to engage in a reflective exercise that is grounded in the group's shared clinical interactions during the session as experienced ("in practice", as Schön would put it $^{14}$ ); as interpreted ("on practice"); and as anticipated ("for practice").

In short, CCPS provides a novel way to learn, teach, and experience psychiatry that garners its pedagogical utility by fostering compassionate curiosity among its learners. From the perspective of safety, CCPS welcomes sharing and revisiting past struggles and challenges in an open, unconditionally supportive, and emotionally secure space. Program leaders, including training directors, need to be strategic in "making" time that is always in short supply in order to make the model become a curricular component: CCPS does not just "happen": it needs to be pursued intentionally through a commitment of time and resources. 
The seeds of CCPS were sown in internal medicine and emergency medicine, ${ }^{40}$ where poor outcomes were commonly grounded not in technical errors, so much as in communication failures. That the model has been refined in mental health is not coincidental: as experts in communication and intersubjectivity, psychiatrists are optimally positioned to make the model not just relevant to their own field but to export it back to other healthcare disciplines. In the process, psychiatrists, as experts in communication, can contribute to their field's destigmatization by showing its worth and unique contributions to the broader house of medicine.

The liminality of the model can be considered from at least two perspectives: First, it is designed to support the transition of learners across developmental turning points, such as when leaving the enveloping security of residency or fellowship and moving into independent practice. Second, CCPS was largely developed through synchronous videoconferencing during the COVID-19 pandemic. The fact that its clinical interactions "rang true" and felt legitimate, and that interactivity and deep reflexivity were possible not only across screens and sites but indeed of latitudes and time zones, opens a wide range of previously unimaginable educational opportunities. For example, CCPS can rely on multicentric expertise where the locus of knowledge and wisdom lie in the social network rather than on any given location's expert. By incorporating the clinical realities, available resources, and social mores of specific sites - even remote ones-CCPS can be tailored locally yet shared broadly, and offers a rubric for the decolonializing of a medical education traditionally grounded in Western, high-income practices that may be of limited resonance, relevance, or applicability.

\section{Conclusions}

In this article, we have articulated a theoretical framework that could inform and refine the governing principles of current psychiatric education. We specifically opt for the term education over training, as we consider that to date much of the energy devoted by psychiatric educators has been centered on the latter, at the expense of the former. Stated alternatively, we consider that efforts to train new cohorts of practitioners have not been sufficiently informed by a deeper review and incorporation of contemporary pegagogy and medical education theories.

By using three variations of a visual term (imaging, image, imagining), we have sought to address different ways in which, through novel educational approaches, psychiatry could address problems in its "optics". But our ultimate goal goes further than addressing extrinsic problems or public relations. We believe that the field as a whole stands to benefit from the approaches we have described. For example, the theoretical underpinnings of our model are rooted in the humanities, and as such can provide avenues through which to reclaim aspects of our field that have been superseded by its biological transformation. As a brain-based approach continues to take hold; in reaction to an entirely mind-based precedent; ${ }^{41}$ and as it seeks legitimacy within modern medicine and the public at large, psychiatry risks disavowing an identity historically rooted in the humanities. Efforts to regain a foothold have mostly focused on strengthening psychotherapy training or in paying more attention to psychosocial afterthoughts to formulations in which the biological has come to prevail.

We conclude with four distilled recommendations. First, psychiatry could take a lead innovating patient simulation in medical education. Specifically, psychiatric education is ideally positioned to move from the prevailing use of standardized patients, to one in which actors, unencumbered by rigid scripts to adhere to, can be utilized as simulated patients instead. ${ }^{21}$ Models such as CCPS that rely on actors' spontaneity can support reflective practice and innovative supervision by opening up a full range of realistic interactions with learners. Second, through their expertise in mental illnesses and the use of intersubjectivity as a means of understanding and healing, psychiatrists can advance the destigmatization of mental health conditions by sharing their own journeys. ${ }^{45}$ A special urgency for recognition and treatment-seeking pertains to fellow healthcare professionals, for whom psychiatrists could serve as role models through their professional and personal expertise. Third, leveraging technologies for interactivity at a distance can open up new possibilities in collaborations that decentralize content expertise, share intellectual resources, and remain nimble in their adjustment lo local realities. Finally, research endeavors to develop and refine all of the applications we have described stand to benefit from the application of qualitative and mixed methods. ${ }^{42}$ We would argue that qualitative methods have been underutilized and overlooked in psychiatric scholarship and are optimally poised to give voice to the lived experience of the patients, families, and communities we serve.

We do not lament the current state of psychiatry as a field, nor of contemporary psychiatric education. But we 
do envision in the model and applications described a range of educational opportunities, should we choose to pursue them and reap their promise.

\section{Acknowledgments}

This work was supported by the Riva Ariella Ritvo Endowment at the Yale School of Medicine, and by NIMH R25 MH077823, 'Research Education for Future Physician-Scientists in Child Psychiatry'.

\section{Disclosure}

The authors report no conflicts of interest in this work.

\section{References}

1. Bhugra D, Sartorius N, Fiorillo A, et al. EPA guidance on how to improve the image of psychiatry and of the psychiatrist. Eur Psychiatry. 2015;30(3):423-430. doi:10.1016/j.eurpsy.2015.02.003

2. Björkenstam E, Ljung R, Burström B, Mittendorfer-Rutz E, Hallqvist J, Weitoft GR. Quality of medical care and excess mortality in psychiatric patients - a nationwide register-based study in Sweden. BMJ Open. 2012;2(e000778):1-10. doi:10.1136/bmjopen-2011-000778

3. Angermeyer MC, van der Auwera S, Carta MG, Schomerus G. Public attitudes towards psychiatry and psychiatric treatment at the beginning of the 21st century: a systematic review and meta-analysis of population surveys. World Psychiatry. 2017;16(1):50-61. doi:10.1002/wps.20383

4. Sartorius N, Gaebel W, Cleveland H, et al. WPA guidance on how to combat stigmatization of psychiatry and psychiatrists. World Psychiatry. 2010;9(3):131-144. doi:10.1002/j.2051-5545.2010.tb00296.x

5. Watkins CE. What do clinical supervision research reviews tell us? Surveying the last 25 years. Couns Psychother Res. 2020;20 (2):190-208. doi:10.1002/capr.12287

6. Sienaert P. Based on a true story? The portrayal of ECT in international movies and television programs. Brain Stimul. 2016;9 (6):882-891. doi:10.1016/j.brs.2016.07.005

7. Stuart H. Media portrayal of mental illness and its treatments: what effect does it have on people with mental illness? CNS Drugs. 2006;20(2):99-106. doi:10.2165/00023210-200620020-00002

8. Bleakley A, Bligh J, Browne J. Medical Education for the Future: Identity, Power and Location. Netherlands: Springer; 2012.

9. Engeström Y. From Teams to Knots. Cambridge: Cambridge University Press; 2008.

10. Latour B. Reassembling the Social: An Introduction to Actor-Network -Theory. Oxford: Oxford University Press; 2007.

11. Wenger E. Communities of Practice: Learning, Meaning, and Identity. Cambridge: Cambridge University Press; 1998.

12. de Carvalho-Filho MA, Tio RA, Steinert Y. Twelve tips for implementing a community of practice for faculty development. Med Teach. 2018;1-7. doi:10.1080/0142159X.2018.1552782

13. Drozdowicz L, Gordon E, Shapiro D, et al. Sexual health in child and adolescent psychiatry: multi-site implementation through synchronized videoconferencing of an educational resource using standardized patients. Front Psychiatry. 2020;11(593101):1-10. doi:10.3389/fpsyt.2020.593101

14. Schön DA. The Reflective Practitioner: How Professionals Think in Action. New York: Basic Books; 1983. doi:10.4135/9781446278611. $\mathrm{n} 14$

15. Kumagai AK, Naidu T. Reflection, dialogue, and the possibilities of space. Acad Med. 2015;90(3):283-288. doi:10.1097/ACM.000 0000000000582
16. Kumagai AK. A conceptual framework for the use of illness narratives in medical education. Acad Med. 2008;83(7):653-658. doi:10.1097/ACM.0b013e3181782e17

17. Hinshaw SP. Another Kind of Madness: A Journey Through the Stigma and Hope of Mental Illness. St. Martin's Press; 2017.

18. Nestel D, McNaughton N, Smith C, Schlegel C, Tierney T. Values and value in simulated participant methodology: a global perspective on contemporary practices. Med Teach. 2018;40(7):697-702. doi:10.1080/0142159X.2018.1472755

19. Cleland JA, Abe K, Rethans JJ. The use of simulated patients in medical education: AMEE Guide No 42 1. Med Teach. 2009;31 (6):477-486. doi:10.1080/01421590903002821

20. Brenner AM. Uses and limitations of simulated patients in psychiatric education. Acad Psychiatry. 2009;33(2):112-119. doi:10.1176/appi. ap.33.2.112

21. Piot M-A, Attoe C, Billon G, Cross S, Rethans JJ, Falissard B. Simulation training in psychiatry for medical education: a review. Front Psychiatry. 2021;12:1-12. doi:10.3389/fpsyt.2021.658967

22. Martin A, Krause R, Jacobs A, Chilton J, Amsalem D. The mental status exam through video clips of simulated psychiatric patients: an online educational resource. Acad Psychiatry. 2019;44(2):179-183. doi:10.1007/s40596-019-01140-9

23. Martin A, Jacobs A, Krause R, Amsalem D. The mental status exam: an online teaching exercise using video-based depictions by simulated patients. MedEdPORTAL. 2020;16(10947):10947. doi:10.15 766/mep_2374-8265.10947

24. Amsalem D, Martin A. Reducing depression-related stigma and increasing treatment seeking among adolescents: randomized controlled trial of a brief video intervention. $J$ Child Psychol Psychiatry. 2021. doi:10.1111/jcpp.13427

25. Kitay B, Martin A, Chilton J, Amsalem D, Duvivier R, Goldenberg M. Electroconvulsive therapy: a video-based educational resource using standardized patients. Acad Psychiatry. 2020;44 (5):531-537. doi:10.1007/s40596-020-01292-z

26. Lewis KL, Bohnert CA, Gammon WL, et al. The Association of Standardized Patient Educators (ASPE) Standards of Best Practice (SOBP). Adv Simul. 2017;2(10):1-8. doi:10.1186/s41077-0170043-4

27. Budd N, Andersen P, Harrison P, Prowse N. Engaging children as simulated patients in healthcare education. Simul Healthc. 2020;15 (3):199-204. doi:10.1097/SIH.0000000000000452

28. Squire TH, Kopić K, Mitchell DC The Ruderman white paper on the challenge to create more authentic disability casting and representation on TV.; 2017. Available from: http://www.rudermanfoundation. org. Accessed November 15, 2021.

29. Amsalem D, Yang LH, Jankowski S, Lieff SA, Markowitz JC, Dixon LB. Reducing stigma toward individuals with schizophrenia using a brief video: a randomized controlled trial of young adults. Schizophr Bull. 2020;46(1):1-8. doi:10.1093/schbul/ sbaal14

30. Thornicroft G, Mehta N, Clement S, et al. Evidence for effective interventions to reduce mental-health-related stigma and discrimination. Lancet. 2016;387(10023):1123-1132. doi:10.1016/ S0140-6736(15)00298-6

31. Scior K, Rüsch N, White C, Corrigan PW. Supporting mental health disclosure decisions: the honest, open, proud programme. $\mathrm{Br}$ J Psychiatry. 2020;216(5):3-5. doi:10.1192/bjp.2019.256

32. Happell B, Scholz B, Bocking J, Platania-Phung C. Promoting the value of mental health nursing: the contribution of a consumer academic. Issues Ment Health Nurs. 2019;40(2):140-147. doi:10.1080/01612840.2018.1490834

33. Knaak S, Modgill G, Patten SB. Key ingredients of anti-stigma programs for health care providers: a data synthesis of evaluative studies. Can J Psychiatry. 2014;59(10):S19-S26. doi:10.1177/ 070674371405901S06 
34. Hankir A, Mahmood J, Houbby N, Ali S, Carrick F, Zaman R. Using experts by personal and professional experience (EPPE) to increase interest in psychiatry as a career at sixth-form level. Psychiatr Danub. 2019;31(Suppl 3):242-248.

35. Martin A, Chilton J, Gothelf D, Amsalem D. Physician self-disclosure of lived experience improves mental health attitudes among medical students: a randomized study. J Med Educ Curric Dev. 2020;7:1-10. doi:10.1177/2382120519889352

36. Martin A, Chilton J, Paasche C, et al. Shared living experiences by physicians have a positive impact on mental health attitudes and stigma among medical students: a mixed-methods study. J Med Educ Curric Dev. 2020;7:1-9. doi:10.1177/2382120520968072

37. Neary S, Ruggeri M, Roman C, Kamauf R, Chilton J, Martin A. Positive impact of self-disclosure through synchronous videoconferencing on attitudes to mental health among physician assistant students: a mixed methods study. J Physician Assist Educ. In press 2021.

38. Martin A, Weller I, Amsalem D, Duvivier R, Jaarsma D, de Carvalho Filho MA. Co-constructive patient simulation: a learner-centered method to enhance communication and reflection skills. Simul Healthc. 2020;15(1):1-7. doi:10.1097/sih.0000000000000528

39. Martin A, Weller I, Amsalem D, et al. From learning psychiatry to becoming psychiatrists: a qualitative study of co-constructive patient simulation. Front Psychiatry. 2021;11(616239):1-15. doi:10.3389/ fpsyt.2020.616239
40. Schweller M, Ledubino A, Cecílio-Fernandes D, de Carvalho-Filho MA. Turning the simulation session upside down: the supervisor plays the resident. Med Educ. 2018;52(11):1203-1204. doi:10.1111/ medu. 13722

41. Eisenberg L. Mindlessness and brainlessness in psychiatry. $\mathrm{Br}$ J Psychiatry. 1986;148(5):497-508. doi:10.1192/bjp.148.5.497

42. Falissard B, Révah A, Yang S, Fagot-Largeault A. The place of words and numbers in psychiatric research. Philos Ethics Humanit Med. 2013;8(1):1-9. doi:10.1186/1747-5341-8-18

43. Fuehrlein B, Hochschild A, Goldman A, Chilton J, Amsalem D, Martin A. Learning about and destigmatizing substance use disorders: a video-based educational resource using simulated patients. Acad Psychiatry. 2021;(0123456789). doi:10.1007/s40596-02101559-z

44. Amsalem D, Markowitz JC, Jankowski SE, et al. Sustained effect of a brief video in reducing public stigma toward individuals with psychosis: a randomized controlled trial of young adults. Am J Psychiatry. 2021;78(7):635-642. doi:10.1176/appi.ajp.2020.20091293

45. Martin A. Healer reveal thyself. Acad Psychiatry. Epub 2021 Nov 9. doi:10.1007/s40596-021-01555-3
Advances in Medical Education and Practice

\section{Publish your work in this journal}

Advances in Medical Education and Practice is an international, peerreviewed, open access journal that aims to present and publish research on Medical Education covering medical, dental, nursing and allied health care professional education. The journal covers undergraduate education, postgraduate training and continuing medical education

\section{Dovepress}

including emerging trends and innovative models linking education, research, and health care services. The manuscript management system is completely online and includes a very quick and fair peer-review system. Visit http://www.dovepress.com/testimonials.php to read real quotes from published authors. 